\title{
Impact of Induced Temperature and Water Stress on Vegetative and Reproductive Parameters of Tomato (Lycopersicum esculantum) Variety Rajitha
}

\author{
M. D. M. Gunawardena and C. S De Silva ${ }^{1}$ \\ Department of Agricultural and Plantation Engineering, The Open \\ University of Sri Lanka
}

\begin{abstract}
The main aim of this research was to study the influence of simulated temperature and water stress on vegetative, reproductive and quality parameters of Tomato (variety Rajitha). Experiments were conducted in the temperature regulated poly tunnel during the growing seasons of 2010 and 2011 in the agricultural field located at Nawala, Nugegoda at the Open University Sri Lanka to evaluate the enhanced temperature (temperature rise by $2{ }^{\circ} \mathrm{C}$ ) and water stress (50\% depletion) effects for Tomato plants. Split plot experiment based on complete randomized design with 10 replicates was applied as experimental design. The plants were grown in pots under temperature-controlled poly tunnels and half of the samples was subjected to water stress (50\% from field capacity), and the rest of the samples were kept at field capacity of soil moisture. Main plot included two different irrigation applications (No water stress, 50\% water stress from the field capacity) and sub plots contained 3 different temperature regimes $\left(34^{\circ} \mathrm{C}\right.$ maximum temperature poly tunnel, $32^{\circ} \mathrm{C}$ maximum temperature poly tunnel, ambient temperature $30^{\circ} \mathrm{C}$ ). Individual water stress showed a highly significant effect on vegetative and reproductive parameters. Tomato fruit setting was minimum at $32-34^{\circ} \mathrm{C}$ temperature range due to pollen sterility. The combined effect of water stress and temperature stress proved to be a significant drawback for vegetative and reproductive growth and also for quality parameters of Tomato. Therefore, Tomato (variety Rajitha) cultivation becomes unsuccessful if there is water and temperature stress condition.
\end{abstract}

Keywords: Tomato, temperature stress, water stress, yield parameters, quality parameters

\footnotetext{
${ }^{1}$ Correspondence should be addressed to Prof. C. S De Silva, Department of Agricultural and Plantation Engineering, Faculty of Engineering Technology, The Open University of Sri Lanka, Nawala, Nugegoda, (Email: csdes@ou.ac.lk)
} 


\section{Introduction}

"Warming of the climate system is unequivocal, as is now evident from observations of increases in global average air and ocean temperatures, widespread melting of snow and ice, and rising global average sea level" (IPCC, 2007). Even with sufficient mitigation measures the current scientific consensus holds that greenhouse gas emissions and atmospheric concentrations are set to increase for some decades. Consequently, global mean surface temperature will continue to rise long after an emissions peak has passed. There is room for debate and uncertainty as to exactly how much warming there will be and at what rate it will unfold, but the general trend of the curve is clear when it concerns about the world average records (IPCC, 2007). Predicted changes in temperature and other climate functions will impact Agro-ecological conditions and food production of the world.

"Tomato" (Solanum lycopersicum) refers to the plant or the edible, typically red, fruit that it bears. Tomato (Solanum lycopersicum) fruit is consumed in diverse ways, such as raw in salads and as an ingredient in many dishes and sauces, and as drinks. The fruit is rich in lycopene, which may have beneficial health effects (Rangana, 1986). In some studies, lycopene, especially in cooked tomatoes, has been found to help prevent prostate cancer (Rangana, 1986). Lycopene has also been shown to improve the skin's ability to protect against harmful UV rays. Natural genetic variation in tomatoes and their wild relatives have given a genetic plethora of genes that produce lycopene, carotene, anthocyanin, and other antioxidants. Tomato varieties which are available will double the normal vitamin C, 40 times normal vitamin A, high levels of anthocyanin (resulting in blue tomatoes), and two to four times the normal amount of lycopene (numerous available cultivars with the high crimson gene).

Amongst vegetable crops, Tomatoes are the most important horticultural crop in the world and grown on over 4 million hectares of land area (FAO, 2004). Tomato is an important popular vegetable crop grown throughout the year in both Maha (October to February) and Yala (March to September) seasons in the dry zone of Sri Lanka. It is a rapidly growing crop with total growing period varying from 90-150 days and also a day neutral plant. Tomato can grow in a wide range of soils but a well drained sandy loam with $\mathrm{pH}$ of 5 to 7 is preferred. Water logging leads to incidence of diseases such as bacterial wilt. The ideal population is about 40000 plants/ha (Anon, 1990 - Department of Agriculture-Techno guide, 2009). 
Tomato is widely cultivated by a considerable portion of farming communities in all agro-ecological zones of Sri Lanka. It is important to study the effects of both temperature and water stress on the growth and yield of this vegetable which may result from global warming. Tomato production is limited by high day time temperature and, especially by high night time temperature (Moore and Thomas, 1952). Peet et al. (1997) which demonstrates that daily mean temperature is more critical than night time temperature. Dinar and Rudich (1985) reported that in Tomato plants, high temperatures affect several physiological and biochemical processes dealing finally with yield reduction. This research aimed to determine the effect of temperature and water stress on vegetative, yield and quality parameters of Tomato (Lycopersicon esculentum) variety, Rajitha as this variety is widely cultivated by farmers for its good marketability.

\section{Methodology}

\section{Induced Environmental Conditions}

All the experiments were conducted at the Open University of Sri Lanka, Nawala, Nugegoda, from September 2009 to April 2011 for the 3 consecutive seasons. Poly tunnels were constructed in order to maintain the stipulated temperature conditions by means of thermostat and air circulation fans (Figure 1). Poly tunnels are $7 \mathrm{~m}$ in length, $3 \mathrm{~m}$ in width and $4 \mathrm{~m}$ in height with a half dome shape top and opened in the middle of the half dome to facilitate the air circulation. One set of poly tunnel was maintained at $32^{\circ} \mathrm{C}\left( \pm 2^{\circ} \mathrm{C}\right)$ maximum temperature and the other set of polytunnel was maintained at $34^{\circ} \mathrm{C}\left( \pm 2^{\circ} \mathrm{C}\right)$. When the temperature increases above the respective maximum temperature, the fans start to operate automatically until the temperature is controlled to the maximum temperature fixed for that particular poly tunnel.

\section{Crop Management}

Tomato (variety Rajitha) seeds were obtained from the Department of Agriculture, Gannoruwa where quality and purity are certified. Nursery was prepared with well aerated and fumigated top soil on a tray and seeds were sown in rows at $1 \mathrm{~cm}$ depth. Tomato seedlings were transplanted into individual plastic pots $(30 \mathrm{~cm}$ diameter and $30 \mathrm{~cm}$ deep). The pots were filled with a compost and reddish brown earth soil mixture. This vegetable was grown at 3 different conditions as explained above. In the management of this crop, recommendation of the agricultural department was adopted for 
fertilizing, weeding etc. except water management (Anon, 1990). N, P and $\mathrm{K}$ fertilizer applications were also followed according to the Department of Agriculture recommendation such as $100 \mathrm{~kg} / \mathrm{ha} \mathrm{N}$, $65 \mathrm{~kg} / \mathrm{ha} \mathrm{P}$, and $160 \mathrm{~kg} / \mathrm{ha} \mathrm{K}$ depending on the soil test. The crop has a fairly deep root system reaching as far as $1.5 \mathrm{~m}$. The maximum rooting depth occurs about 60 days after transplanting resulting in a maximum $\mathrm{ET}_{\mathrm{o}}$ of $6 \mathrm{~mm} /$ day. The plants are adversely affected when more than 40 present of the total available soil water has been depleted (Doorenbos and Kassam, 1979).

Chemical control of pest and diseases was done by application of Atabron (a.i. chlorfluazuron) and Vondozeb (a.i. Mancozeb) at 4, 6 and 8 WAP. In addition, pegging at 4WAP, application of top dressing at 3 and $6 \mathrm{WAP}$ and regular observations were done.

(a)

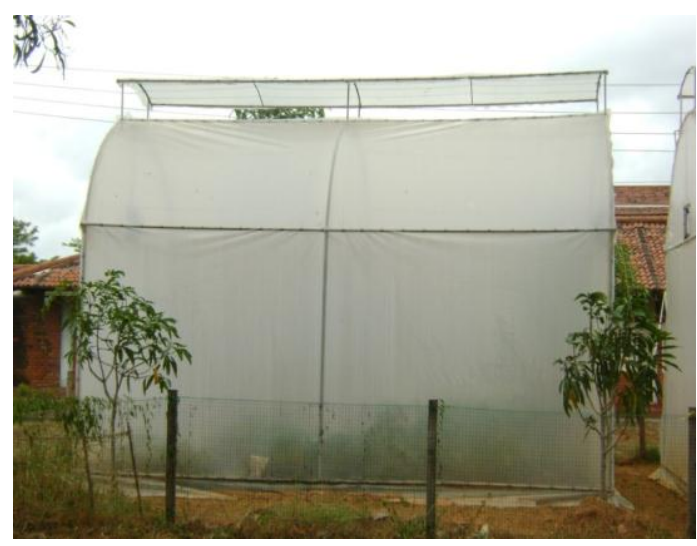

(b)

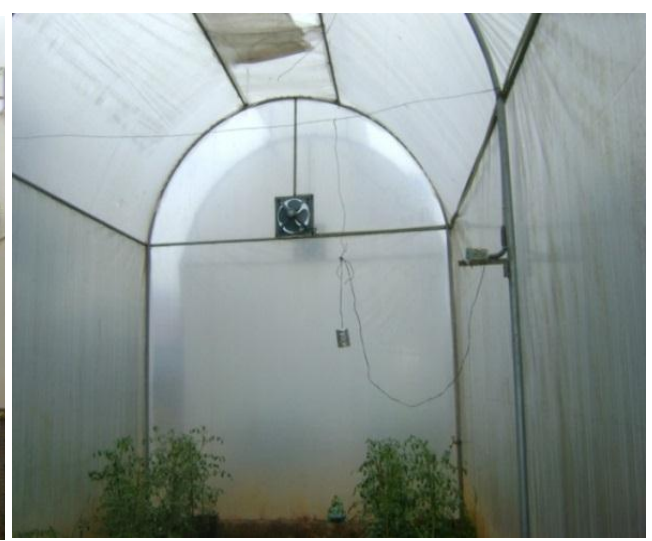

Figure1. Temperature regulated poly tunnel (a) outside and (b) inside

\section{Experimental Design and Statistical Analysis}

The experiment was laid out at split plot experimental design in a complete randomized manner with ten replicates for the main plot treatment. The main plot included two different soil moisture conditions by irrigating such as field capacity (no water stress) and $50 \%$ of the field capacity imposed (water stress) while the sub plots contained 3 different temperature regimes; $34^{\circ} \mathrm{C}$ (maximum), $32^{\circ} \mathrm{C}$ (maximum) and ambient temperature at open space. Soil moisture measurements were carried out using tensiometer. Data were analyzed using split plot analysis of variance. There were two factors i.e., temperature stress and water stress. All extraction runs and analyses were carried out at least in duplicate and in randomized 
order with the mean values being reported. Analysis of variance (ANOVA) of the results was performed using General Linear Model procedure of SPSS (Software Version 19). Multiple comparison of the various means were carried out by LSD (Least Significant Difference) test at $\mathrm{P}=0.05$ and $\mathrm{p}=0.01$ as the usual procedure.

\section{Irrigation Levels}

The soil water content in half of the pots was kept at field capacity by compensating the loss in weight by adding water. Each pot was filled with $5 \mathrm{~kg}$ of air dried soil. Other normal agronomic practices for each crop were followed. Two water regimes were imposed which were well-watered treatment at field capacity and water stress imposed by reducing the soil water content until 50\% of the field capacity level .

Soil moisture was determined prior to each irrigation event and daily rainfall and pan evaporation data were recorded. Soil bulk density was measured to calculate volumetric water content of soil. The upper limit (field capacity) and the lower limit of the available soil moisture contents of volumetric basis were considered as $28 \%$ and $16 \%$ respectively.

Soil field capacity was calculated on soil dry weight basis. Water stress treatments were, imposed when the plants were established. Only the deficit amount of moisture was added to the root zone to attain field capacity. Before starting addition of water, Tensiometer was fixed to the soil of the polyethylene encircled root zone.

\section{Evaluating Vegetative and Reproductive Parameters of Tomato Plants}

The transplant success (survival rate) was estimated by the percentage of plants that showed successful establishment at 3 weeks after planting (WAP). Morphological and yield parameters of Tomato were investigated during the growing and reproductive periods. Chemical control of pest and diseases was done by application of Atabron (a.i. chlorfluazuron) and Vondozeb (a.i. Mancozeb) at 4, 6 and 8 WAP. In addition, stalking at 4 WAP, application of top dressing at 3 and $6 \mathrm{WAP}$ and regular observation were being made. Number of leaves, leaf area index (LAI) and plant height was measured at weekly intervals up to 6 weeks after flowering (WAF) as morphological parameter. Numbers of leaves per plant were counted once for two weeks. The number of leaves on the main stem (primary leaves) and the rest of the leaves on the shoots 
subtending the primary flowers which were longer than $1 \mathrm{~cm}$ (secondary leaves) were counted and totaled to determine effects on leaf initiation.

Leaf area index (LAI) was determined directly by taking a nondestructive sample of foliage from a plant canopy, measured the leaf area per sample plot, and divided it by the plot land surface area. For that, three replicated plants per each treatment were selected for the study. Leaves were sampled from different levels of the canopy, twenty each from replicated plants, during the fullfoliage period in growing seasons. Each leaf was spread over millimeter graph paper, and the outline of leaf was drawn. Using the paper knife, the area of the millimeter graph paper covered by the outline was cut and weighed on an electronic balance. One $\mathrm{cm}^{2}$ of the same millimeter graph paper was also cut and weighed. The following equation was used to calculate the leaf area nondestructively:

$$
\text { Leaf area }(\mathrm{cm} 2)=\frac{\mathrm{X}}{\mathrm{Y}}
$$

Where

$\mathrm{X}$ is the weight of the graph paper covered by the leaf outline $(\mathrm{g}) \mathrm{Y}$ is the weight $(\mathrm{g})$, of the $\mathrm{cm}^{2}$ area of the graph paper.

The plant height of 15 randomly selected plants (five plants per each replicates) was recorded in each treatment from ground level to the tip of plants by means of meter rod and average height of plant was calculated.

Time of flowering (days to attain $50 \%$ or $100 \%$ flowering at weekly interval), flower production (number of flowers per week), and fruit set (number of fruits per week) were recorded to study the flowering behaviour and fruit production under different treatments.

Due to temperature and water stress, there were changes in vegetative growth stages of the crops before getting in to reproductive growth as fruit pods. Therefore, parameters such as fruit yield per plant $(\mathrm{g})$, fruit weight $(\mathrm{g})$, number of fruits per plant, and plant height $(\mathrm{cm})$ were measured weekly. 


\section{Results and Discussion}

\section{Temperature and Water Stress Effect on Growth Parameters of Tomato}

\section{Transplant Success}

The results of vegetative parameters for the mean of three seasons are presented in Table 1. Mean value of transplant success percentage for different treatments were compared, $32^{\circ} \mathrm{C}$ maximum temperature with no water stress had the highest significant $(\mathrm{P} \leq$ 0.05 ) transplant success of $93.67 \%$ followed by ambient temperature with no water stress $(93.3 \%), 34^{\circ} \mathrm{C}$ maximum temperature with no water stress $(92.15 \%)$, ambient temperature with $50 \%$ water stress $(76.20 \%) \quad 32^{\circ} \mathrm{C}$ maximum temperature with $50 \%$ water stress $(70.20 \%)$ and $34^{\circ} \mathrm{C}$ maximum temperature with $50 \%$ water stress $(64.05 \%)$ respectively (Figure 2). However, the transplant success showed a significant decline with water stress while the combination of water and temperature stresses have resulted in the lowest transplant success due to enhancement of the plant stress (Table 1 and 2).

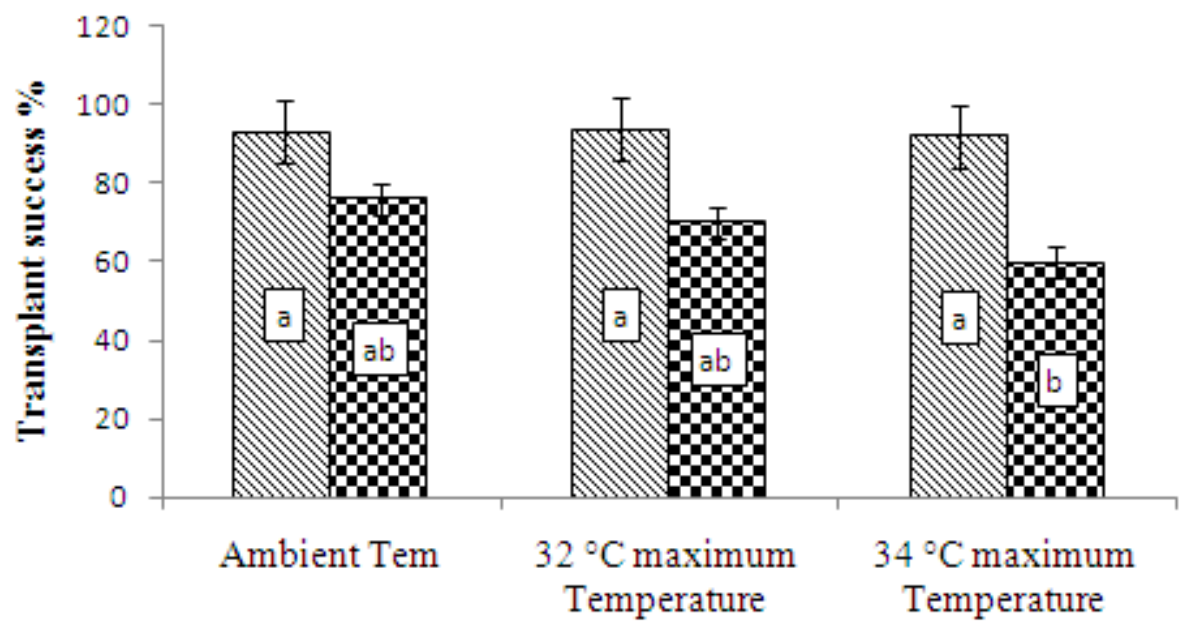

\$No water stress $\quad 50 \%$ water stress

Figure 2. Effect of treatments on transplant success of tomato seedlings 
Stresses restraint can result in hardened or stress-tolerant seedlings. This stress tolerance is important for transplanting when field establishment cannot be done immediately or sustained under future predicted hazards (Marr and Jirak, 1990). The goal in transplant production is to achieve an optimal seedling size with the appropriate level of stress tolerance to withstand environmental or other stresses when the plugs are transplanted into the field.

\section{Plant Height}

Based on the results on plant height, it was clear that, plants which received more water could grow well and accumulate a higher amount of fresh and dry matter in the shoots. Mature plants, which received enough water without any limitation, had significantly higher stems. These results indicate that water stress on the plants may significantly reduce the vegetative growth of tomato (Table 1). Imposed water stress decreases plant height and shoot growth, but this is not statistically significant at 3 and 6 weeks after transplanting. When comparing the mean value of plant height at three weeks after planting (3WAP) for different treatments, both $32^{\circ} \mathrm{C}$ maximum temperature with no water stress and $34^{\circ} \mathrm{C}$ maximum temperature with no water stress had shown the highest plant height of $21.3 \mathrm{~cm}$ followed by $34^{\circ} \mathrm{C}$ maximum temperature with $50 \%$ water stress $(19.20 \mathrm{~cm}), 32^{\circ} \mathrm{C}$ maximum temperature with $50 \%$ water stress $(18.93 \mathrm{~cm})$, ambient temperature with no water stress $(18.10 \mathrm{~cm})$ and ambient temperature with $50 \%$ water stress $(17.63$ $\mathrm{cm})$ respectively (Figure 3 ).

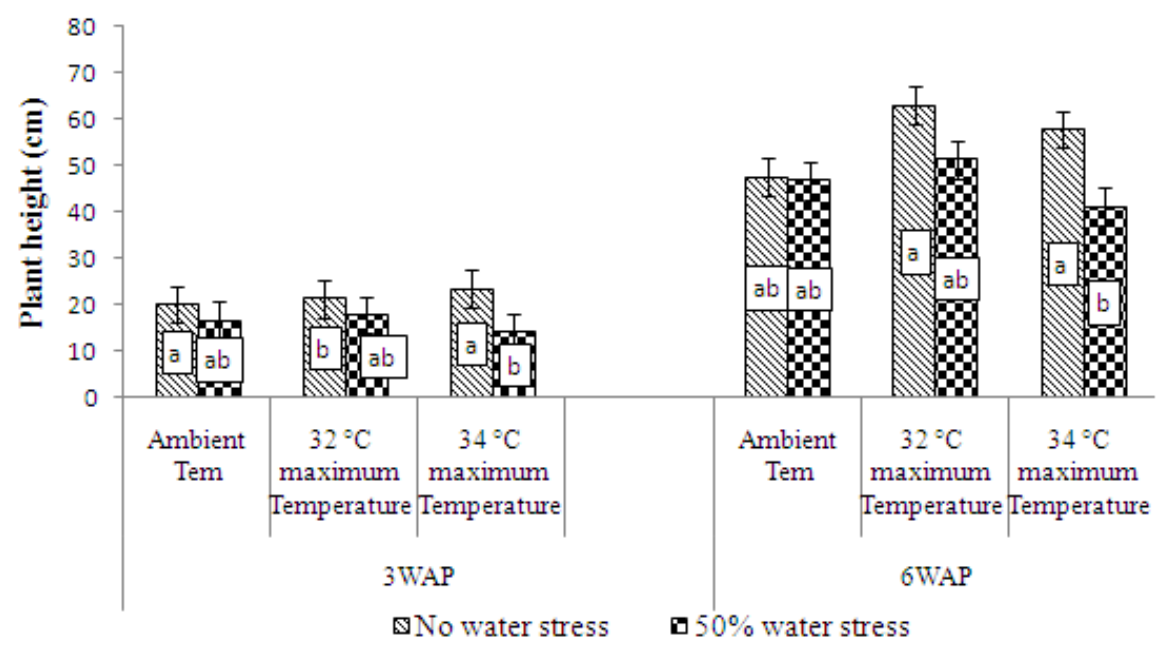

Figure 3. Effect of treatments on plant height at three weeks and six weeks after planting 
Plant height at six weeks after planting $(6 \mathrm{WAP}), 32^{\circ} \mathrm{C}$ maximum temperature with no water stress had shown the highest plant height of $63.16 \mathrm{~cm}$ followed by $34^{\circ} \mathrm{C}$ maximum temperature with no water stress $(58.01 \mathrm{~cm}), 32^{\circ} \mathrm{C}$ maximum temperature with $50 \%$ water stress $(51.36 \mathrm{~cm}), 34^{\circ} \mathrm{C}$ maximum temperature with $50 \%$ water stress $(49.20 \mathrm{~cm})$, ambient temperature with no water stress $(47.64 \mathrm{~cm})$ and ambient temperature with $50 \%$ water stress $(46.89$ $\mathrm{cm}$ ) respectively (Figure 3).

Although combine stress treatment showed the lowest plant height at both 3 and 6 WAP, it did not significantly effect the reduced shoot growth. Similarly Adil et al (2003) shows that plant height was generally reduced when subjected to heat shock treatment at $37^{\circ} \mathrm{C}$.

\section{Leaf Number}

The effect of water and temperature stress conditions on leaf number at 3 week after planting and 6 week after planting is respectively shown in Figure 4 . When comparing mean value of leaf number at three weeks after planting (3WAP) for different treatments, no water stress at $34^{\circ} \mathrm{C}$ maximum temperature had shown the highest leaf number of 33.5 followed by and $32^{\circ} \mathrm{C}$ maximum temperature with no water stress $(28.67), 34^{\circ} \mathrm{C}$ maximum temperature with $50 \%$ water stress (25.17), ambient temperature with no water stress (25), $32^{\circ} \mathrm{C}$ maximum temperature with $50 \%$ water stress (21.33), and ambient temperature with $50 \%$ water stress (20.33) respectively (Figure 4). Leaf number at six weeks after planting (6WAP), $32^{\circ} \mathrm{C}$ maximum temperature with no water stress had shown the highest leaf number of 49 followed by $34^{\circ} \mathrm{C}$ maximum temperature with no water stress (46), ambient temperature with no water stress $(35.5), 34^{\circ} \mathrm{C}$ maximum temperature with $50 \%$ water stress $(31), 34^{\circ} \mathrm{C}$ maximum temperature with $50 \%$ water stress $(49.20 \mathrm{~cm})$, ambient temperature with 50\% water stress (28) and ambient temperature with 50\% water stress (27.5) respectively. Significantly high leaf number at 0.05 probability level was shown by no water stress treatment at 3WAP (Figure 4). 


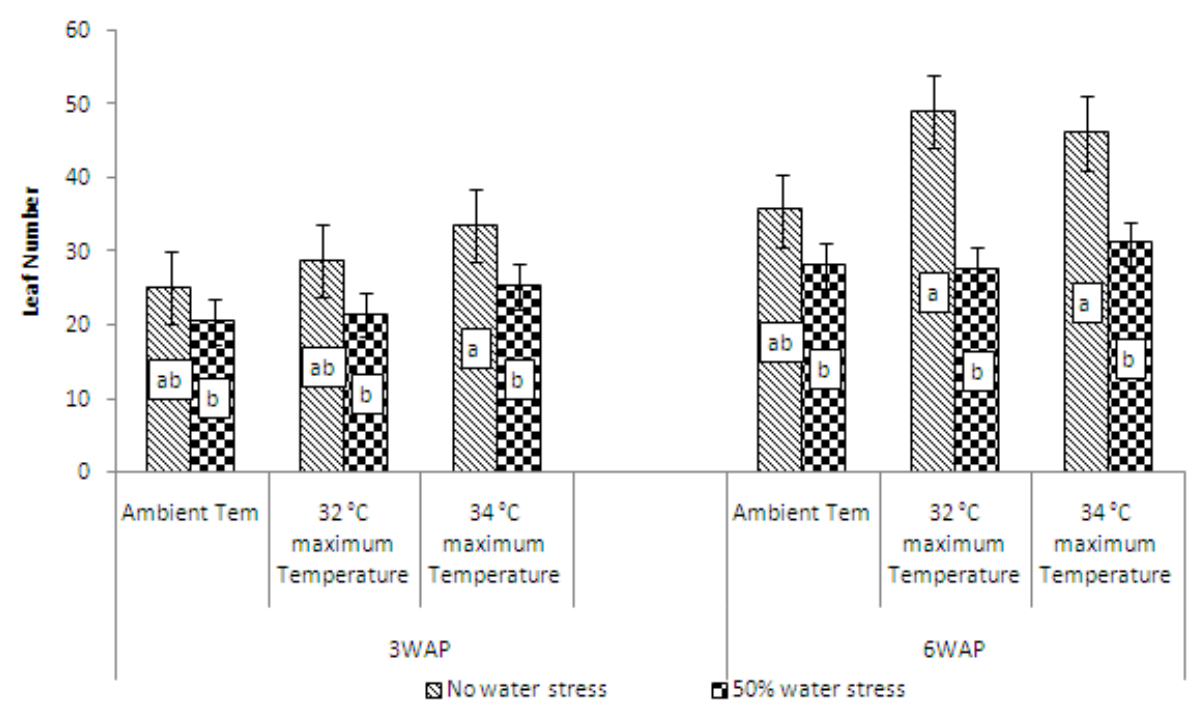

Figure 4. Effect of treatments on leaf number at three weeks and six weeks after planting

Temperature and Water Stress Effect on Yield Parameters of Tomato

\section{Flowering}

With respect to flower formation and fruit setting the number of flowers formed at 9, 11, 13, and 15 WAP are illustrated in Figure 5. Early flowering was observed in plants kept at higher temperatures similar to the report of Weerakkody and Peris (1996) where early flowering of tomato in the indoor culture was a result of the vigorous vegetative growth of the plants. Although there was early flowering, there was no significant variation $(p \geq 0.05)$ of number of flower/plant among the treatments. 


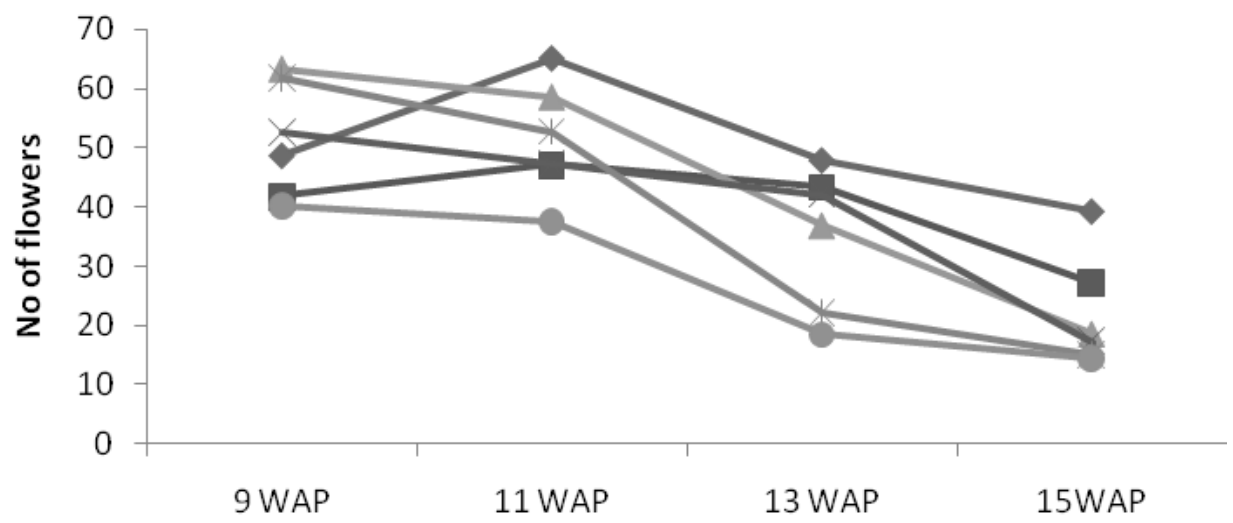

$\longrightarrow$ Ambient tem. No water stress $\quad-$ Ambient tem. $50 \%$ water stress

$\leftarrow-32^{\circ} \mathrm{C}$ Max. tem No water stress $\longleftarrow 32^{\square} \mathrm{C}$ Max. Tem $50 \%$ water stress

* $34{ }^{\circ} \mathrm{C}$ Max. Tem No Water stress $-34{ }^{\mathrm{D}} \mathrm{C}$ Max. tem $50 \%$ Water stress

Figure 5. Effect of treatments on Flowering 

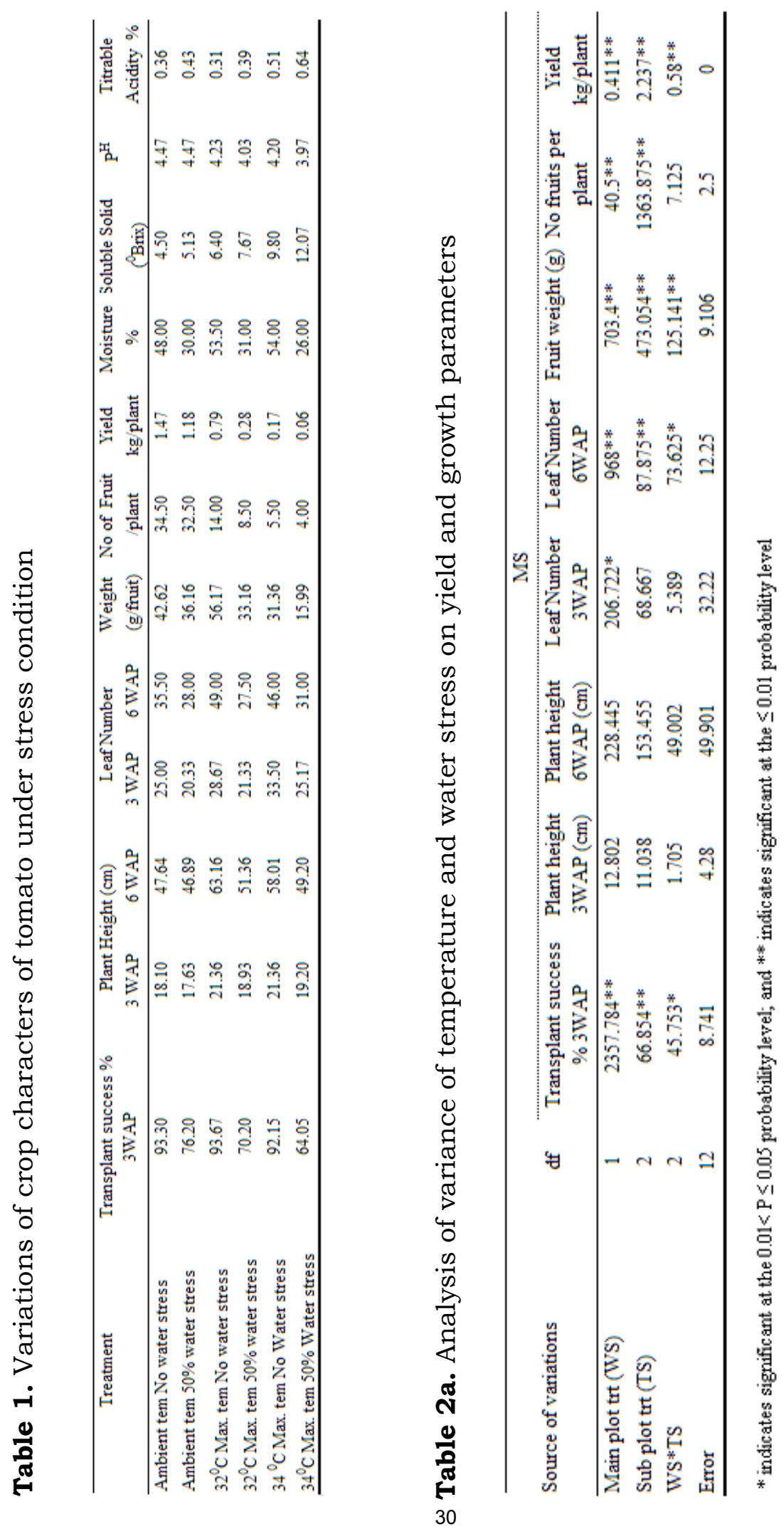


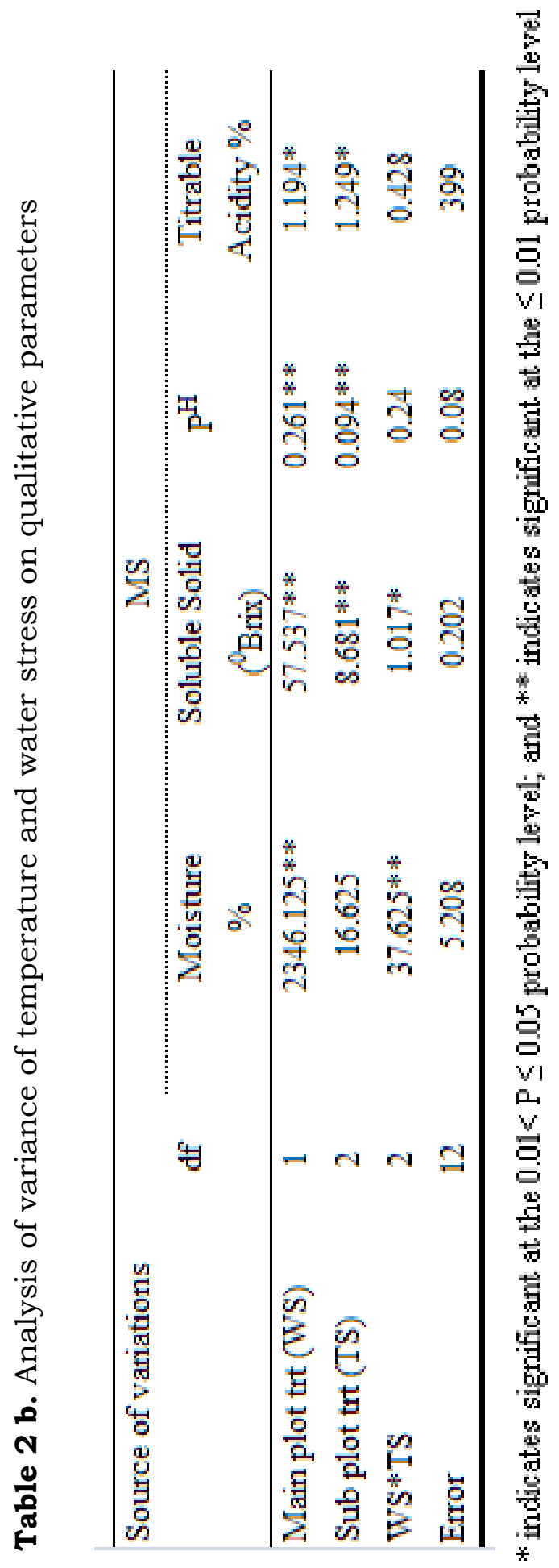




\section{Fruit Weight}

When comparing the mean value of fruit weight for different treatments, $32^{\circ} \mathrm{C}$ maximum temperature with no water stress had shown the highest fruit weight of $56.17 \mathrm{~g}$ followed by ambient temperature with no water stress $(42.62 \mathrm{~g})$, ambient temperature with $50 \%$ water stress $(36.16 \mathrm{~g}), 32^{\circ} \mathrm{C}$ maximum temperature with water stress, $34^{\circ} \mathrm{C}$ maximum temperature with no water stress $(31.36 \mathrm{~g})$ and $34^{\circ} \mathrm{C}$ maximum temperature with $50 \%$ water stress $(15.99$ g) respectively (Figure 6). High temperatures can cause significant losses in Tomato productivity due to reduced fruit set, and smaller and lower quality fruits (Stevens and Rudich, 1978). Abdalla and Verderk (1968) showed that vegetative and reproductive processes in tomatoes are strongly modified by temperature alone or in conjunction with other environmental factors. High temperature stress disrupts the biochemical reactions fundamental for normal cell function in plants. It primarily affects the photosynthetic functions of higher plants (Weis and Berry 1988).

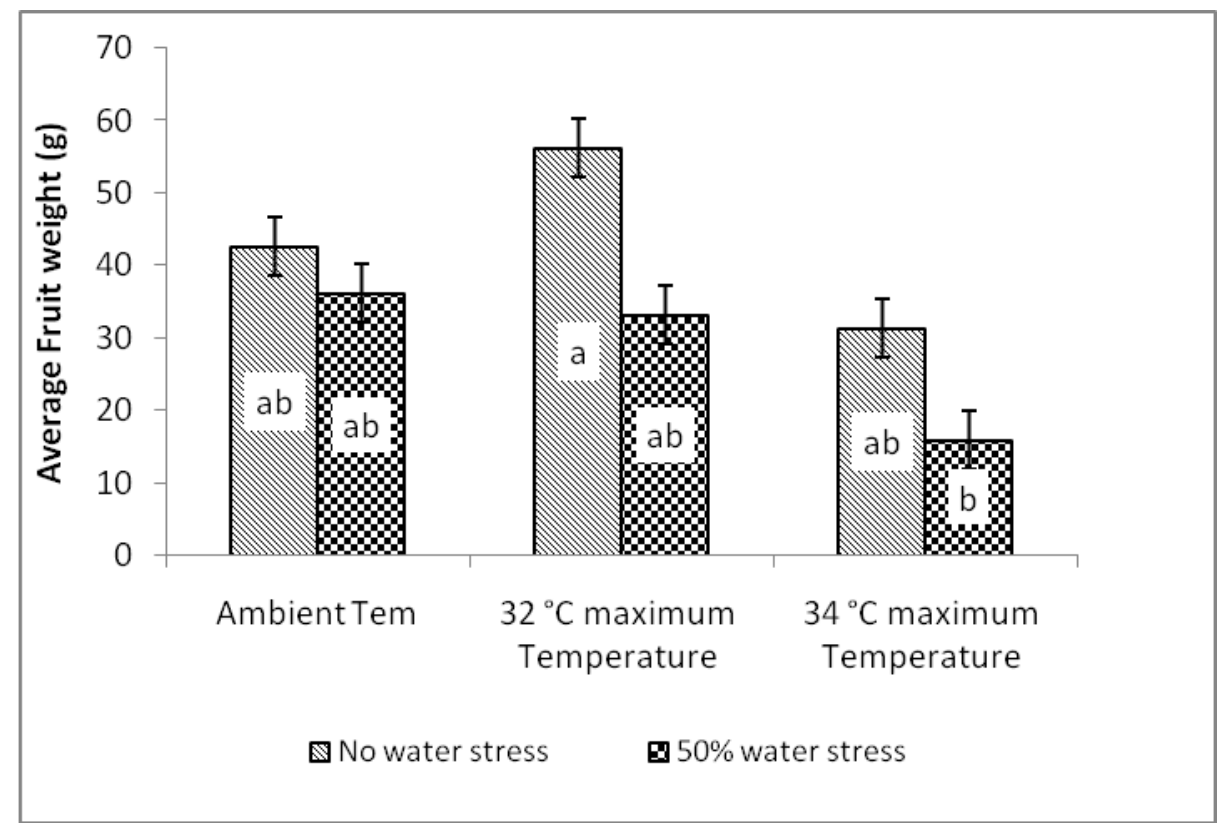

Figure 6. Effect of treatments on average fruit weight

\section{Number of Fruits per Plant}

When comparing mean value of number of fruits per plant for different treatments, ambient temperature with no water stress had shown the highest fruit number 34.5 followed by ambient 
temperature with no water stress $(32.5), \quad 32^{\circ} \mathrm{C}$ maximum temperature with no water stress $(14.00), 32^{\circ} \mathrm{C}$ maximum temperature with $50 \%$ water stress $(8.5), 34^{\circ} \mathrm{C}$ maximum temperature with no water stress (5.5), and ambient temperature with $50 \%$ water stress (4) respectively (Figure 7 ).

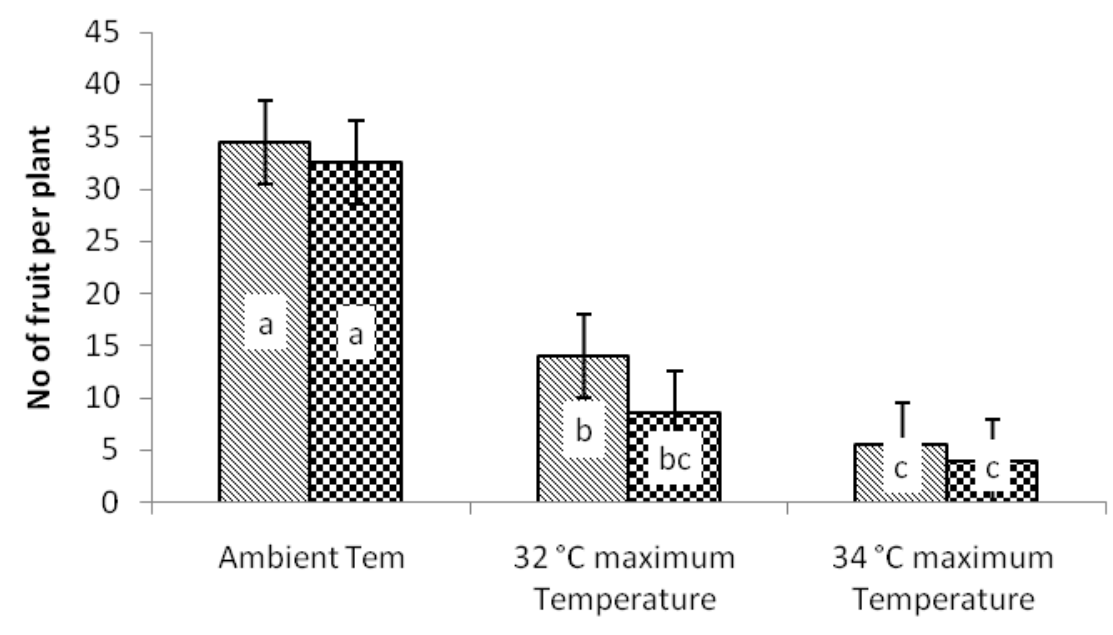

$\mathbb{N}$ No water stress

D $50 \%$ water stress

Figure 7. Effect of treatments on number of fruit per plant

\section{Fruit Yield}

Fresh fruit yield, fresh fruit weight, fruit number per plant and crop residue weight (vegetative biomass) of tomato were significantly different among treatments. The interaction effect resulted the highest mean yield $(1.47 \mathrm{~kg} /$ plant $)$ in plants grown in outdoor ambient temperature without water stress, followed by outdoor grown plants with water stress $(1.175 \mathrm{~kg} /$ plant) (Figure 8). The potential yield range of tomato with the application of recommended chemical fertilizer is 20 to $30 \mathrm{t} /$ ha (Anon, 1990-Department of Agriculture Crop recommendation - Techno guide).

Therefore, above yield of tomato in ambient temperature (outdoor condition) without water stress is in the potential yield range of tomato. Although the vegetative growth was higher and early flowering occur at the $32^{\circ} \mathrm{C}$ temperature, the yield was low $(0.78$ $\mathrm{kg} /$ plant) and with water stress it was further reduced to 0.281 $\mathrm{kg} /$ plant. Meanwhile the yield obtained at $34^{\circ} \mathrm{C}$ maximum temperature was $0.172 \mathrm{~kg} /$ plant and with water stress it was further 
reduced to $0.063 \mathrm{~kg} /$ plant. Hence loss of pollen viability could be a main reason for the lower fruit set under high ambient temperatures. Adil et al., (2003) showed reproductive processes in tomato were more sensitive to high temperatures than the vegetative process. The number of pollen grains produced by the heat tolerant genotypes was higher than the numbers produced by the heat sensitive genotypes.

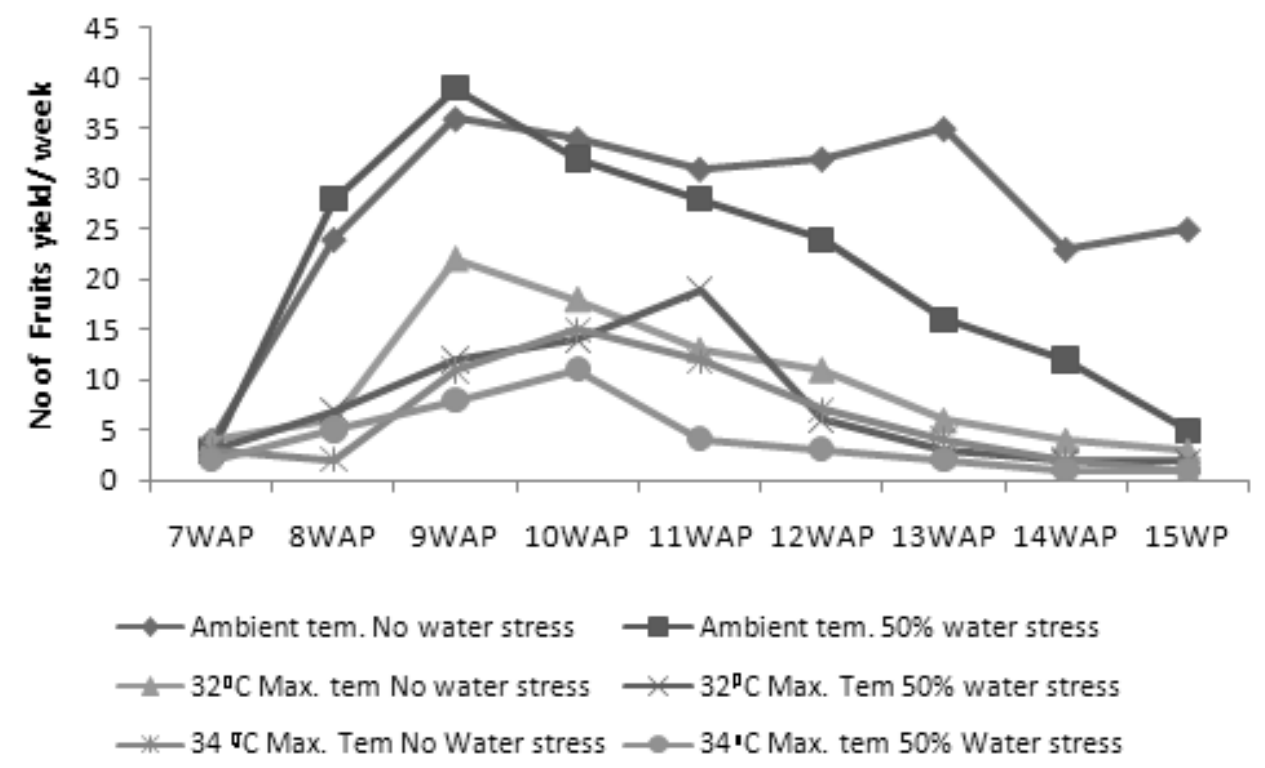

Figure 8. Number of fruits counted for different treatments

Etanpressman et al, (2002), and Adil et al., (2003) demonstrated that continuous exposure of fruit truss to high temperatures markedly reduced the number of pollen grains per flower and decreased viability. The effect of heat stress on pollen viability was associated with alterations in carbohydrate metabolism in various parts of the anther during its development. High post-pollination temperatures inhibited fruit set, suggesting that fertilization is sensitive to high temperature stress (Erickson and Markhart, 2002). Hazra et al. (2007) summarized the symptoms causing fruit set failure at high temperatures in tomato; this includes bud drop, abnormal flower development, poor pollen production, dehiscence, and viability, ovule abortion and poor viability, reduced carbohydrate availability, and other reproductive abnormalities. In addition, significant inhibition of photosynthesis occurs at temperatures above optimum, resulting in considerable loss of potential productivity. 
A pattern of yield variation among treatments is well supported by data on fruit size and number. At temperature of $34^{\circ} \mathrm{C}$ without water stress produced the lowest number of fruits per plant (5.5) while plants grown under ambient temperatures (out door) produced the highest number of fruits per plant. Both fruit weight and size significantly reduced when water stress was imposed. Fruits at the ambient temperature and $32^{\circ} \mathrm{C}$ without water stress were heavier than those in the other treatments. $34^{\circ} \mathrm{C}$ maximum temperature with $50 \%$ water stress produced the smallest fruits. Fruit grew heavier in plants grown with adequate soil moisture during stages of vegetative growth and fruit setting. Similarly Molla Md et al., (2003) showed that the water stress throughout the growing season significantly reduced yield and fruit size.

\section{Conclusions}

According to the results, water and temperature stresses and their interaction significantly effect on the growth and yield parameters such as plant height, fresh weight, number of fruit per plant, fruit yield etc. Temperature stress was positive on the plant height and shoot and leaf formation under indoor condition. Water and temperature stress in combination had severe negative effects on growth parameters as compared to the individual water stress treatments. The combination effect of water stress and temperature stress exert significant drawbacks on tomato (variety Rajitha) plant growth, fruit quality, and the chemical composition of the fruit. Throughout the season or during the early stage of ripening, and at fruit growth, combination of temperature and water stress leads to severe yield reductions of the crop. Tomato variety Rajitha, showed severe crop failures and thus negative effects on the overall yield and growth characters. Therefore, tomato variety Rajitha can not be identified as a successful crop for the dry zone of Sri Lanka if temperature is increased due to global warming. However, tomato could be successfully cultivated under green house conditions by providing adequate water and the required kind of soil and air temperature management practices.

\section{Acknowledgement}

Authors acknowledge the National Science Foundation (NSF), Sri Lanka's research grant (RG/2008/AG/04) given to the second author of this paper and the valuable contributions of the committee of NSF during the progress review of this research study. 


\section{References}

Abdalla, A. A, \& Verderk, K. (1968). Growth, flowering and fruit set of tomato at high temperature. The Neth J Agric Sci 16:71-76.

Adil H. Abdelmageeda, Nazim Grudab \& Bernd Geyerb (2003). Effect of High Temperature and Heat Shock on Tomato (Lycopersicon esculentum Mill.) Genotypes under Controlled Conditions University of Khartoum, Department of Horticulture, Sudan Humboldt-Universität zu Berlin, Institute for Horticultural Science, Department of Vegetable Crops,Lentzeallee 75, 14195 Berlin, Germany. Email: nazim.gruda@rz.hu-berlin.de

Anon. (1990). Technoguide, p 86-92. Department of Agriculture, Peradeniya.

Dinar, M., \& Rudich, J. (1985). Effect of heat stress on assimilates partition in tomato. Ann. Bot. 56: 239-249.

Erickson, A. N., \& Markhart A. H (2002). Flower developmental stage and organ sensitivity of bell pepper (Capsicum annuum L) to elevated temperature. Plant Cell Environ 25:123-130.

Etanpressman, M. P., \& Mason, P., (2002). The Effect of Heat Stress on Tomato Pollen Characteristics is associated with Changes in Carbohydrate Concentration in the Developing Anthers: Annals of Botany [on line]. Available at http://aob.oxfordjournals.org/cgi/content/full/90/5/631

FAO (2004) Impact of climate change on agriculture in Asia and the Pacific. Twenty-seventh FAO Regional Conference for Asia and the Pacific. Beijing, China, 17-21 May 2004.

Hazra P, Samsul H. A., Sikder, D. \& Peter, K.V (2007) Breeding tomato (Lycopersicon Esculentum Mill) resistant to high temperature stress. Int J Plant Breed 1(1).

IPCC. (2007). Fourth Assessment Report of the Intergovernmental Ppanel for Climate Change. New York: Cambridge University Press.

Marr, C., \& Jirak, M. (1990). Holding Tomato transplants in plug trays. HortScince, 25, 173-176.

Molla, M. D., Madramootoo Chandra, A. \& DODDS Georges, T. (2003) Effects of water stress at different growth stages on 
greenhouse tomato yield and quality: McGill University, 21111 Lakeshore Road, Montreal, QC, H9X 3V9, CANADA [on line].

http: / / cat.inist.fr $/$ ?aModele=afficheN\&cpsidt $=15421402$.

Moore, E. L \& Thomas, W. O. (1952). Some effects of shading and paracholorophenoxy acetic acid on fruitfulness of tomatoes. Proceedings of the American Society for Horticulture science 60: 289-294.

Peet, M. M, Willits, D. H \& Gardner, R. G. (1997). Response of ovule development and post pollen production process in male sterile tomatoes to chronic, sub-acute high temperature stress. Journal of experimental botany 48: 101-111.

Ranganna. S. (1986) Hand book of Analysis and Quality control for fruits for Fruits and Vegetable production, $2^{\text {nd }}$ edition, Tata McGraw hill publishing Company and Ltd. New Delhi

Stevens M. A \& Rudich J (1978) Genetic potential for overcoming physiological limitations on adaptability, yield, and quality in tomato. Hort Science 13:673 -678.

Weerakkody, W. A. P. \& Peiris, B. C. N. (1996). Effect of rainfall during growth stages on vegetative growth and flowering of tomato. Proc. $5^{\text {th }}$ staff Res. Sessions of fac. of Agric, University of Peradeniya. Pp. 39-41.

Weis, E. \& Berry J. A. (1988) Plants and high temperature stress. Soc of Expt Biol, pp 329-346.

Received: 27-1-2015 Revised: 5-6-2015 Accepted: 8-6-2015 